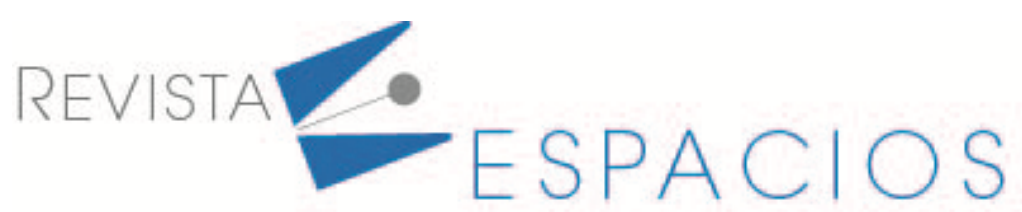

\title{
Biología, productividad y atributos comerciales del molusco bivalvo "concha prieta» (Anadara tuberculosa)
}

\section{Biology, productivity and commercial attributes of the «black ark Shell» bivalve mollusk (Anadara tuberculosa)}

\author{
PRADO-CARPIO, Eveligh C. ${ }^{1}$ \\ MARTÍNEZ-SOTO, Moisés E. ${ }^{2}$ \\ RODRÍGUEZ-MONROY, Carlos ${ }^{3}$ \\ QUIÑONEZ-CABEZA, Manuel ${ }^{4}$ \\ OLIVO-GARRIDO, María L. ${ }^{5}$
}

\begin{abstract}
Resumen
Se describe la biología y productividad de $A$. tuberculosa (concha prieta), enfatizando sus atributos comerciales. Se realizó una investigación bibliográfica. Se analizan: indicadores morfométricos (largo, ancho, alto, peso total y fresco); captura por unidad de esfuerzo, densidad y tasa de crecimiento; atributos comerciales (talla, frescura, calidad nutricional y el cumplimiento de normas internacionales sobre calidad sanitaria e inocuidad). Se concluye que los aspectos biológicos y la productividad guardan relevante relación con los atributos comerciales, esencial para alcanzar su producción sostenible.

Palabras clave: molusco bivalvo, productividad, atributos comerciales, indicadores morfométricos
\end{abstract}

\begin{abstract}
It describes the biology and productivity of $A$. tuberculosa (prieta shell), emphasizing its commercial attributes. A literature review has been carried out. The following characteristics are analyzed: morphometric indicators (length, width, height, total and fresh weight); capture per unit of effort, density and growth Rate; attributes (size, freshness, nutritional quality and compliance with international standards on health quality and safety). It is concluded that biological aspects and productivity are relevant to commercial attributes, essential to achieving sustainable production.

Keywords: bivalve mollusk, productivity, commercial attributes, morphometric indicators
\end{abstract}

\footnotetext{
${ }^{1}$ Docente Investigadora. Unidad Académica de Ciencias Agropecuarias. Universidad Técnica de Machala. Ecuador. Correo: eprado@utmachala.edu.ec.

2 Docente Investigador. Facultad de Agronomía. Núcleo Agropecuario. Universidad del Zulia. Maracaibo, Venezuela, Correo: moisesenriquemartinezsoto@fa.luz.edu.ve.

${ }^{3}$ Docente Investigador. Escuela Técnica Superior de Ingenieros Industriales. Universidad Politécnica de Madrid. España. Correo: crmonroy@etsii.upm.es

4 Docente Investigador. Universidad Técnica Luis Vargas Torres de Esmeraldas, Ecuador. Correo: ruvin1967@gmail.com

${ }^{5}$ Docente Investigadora. Facultad de Medicina, Universidad Central de Venezuela, Caracas, Venezuela, lourdesolivo@gmail.com
} 


\section{Introducción}

A lo largo del tiempo, la actividad pesquera ha evolucionado e incorporado diferentes tecnologías en construcción naval, comunicaciones, navegación y métodos de detección de recursos, entre otras. Sin embargo, en muchas regiones del mundo por razones de diverso tipo (ecológicas, culturales, sociales y económicas), los pescadores siguen utilizando artes y métodos de pesca tradicionales, que han evolucionado poco en el tiempo, tal es el caso de la pesquería de la concha prieta (Anadara tuberculosa).

Según Arriga y Martínez (2003), la pesca artesanal comprende modalidades que van desde la ancestral recolección a mano de mariscos hasta el uso de embarcaciones motorizadas que operan en aguas someras y en el mar abierto. Su característica básica es la operación manual de las artes de pesca, que se clasifica en: pesca de recolección, pesca artesanal costera y pesca artesanal oceánica.

La pesca de recolección se orienta a la extracción de conchas, cangrejos, almejas, mejillones, pulpos, langosta, camarones, jaibas, larveros, hembras ovadas de camarón y larvas de camarón. A efectos de esta investigación, se destacará la extracción que se realiza en las zonas de manglar. Las especies comerciales más importantes reportadas en el ecosistema manglar ecuatoriano son las llamadas popularmente conchas: prieta o hembra (Anadara tuberculosa), la mica o macho (Anadara similis) y la pata de mula (Anadara grandis), además del cangrejo rojo (Ucides occidentalis).

Las especies del género Anadara son altamente apreciadas y están sometidas a una explotación intensiva a lo largo del litoral. De las tres especies mencionadas, A. tuberculosa es la más abundante y la que más contribuye en términos de producción pesquera, constituyendo la principal especie de molusco bivalvo explotada en las costas ecuatorianas (MacKenzie y Clyde, 2001), con grandes potencialidades económicas para el sector de la pesca artesanal (García-Domínguez, Haro-Hernández, García-Cuellar, Villalejo-Fuerte y Rodríguez-Astudillo, 2008).

A. tuberculosa es una especie endémica de los bosques de manglares del Pacifico americano. Esta actividad de origen ancestral y de naturaleza local tiene gran relevancia económica, social y ambiental, pues representa el medio de sustento de miles de familias de recolectores de conchas en todos estos países, así como fuente de alimentación a las comunidades costeras.

Los países asiáticos son grandes productores de moluscos del género Anadara y el sistema de cultivo es básicamente extensivo a partir de la colecta de semilla silvestre que es propagada en zonas de manglar. El cultivo de este bivalvo, se inició en China desde el siglo 17, mientras que en Japón el cultivo exitoso de Anadara granosa data de 1959 (Mazón-Suástegui, Robles-Mungaray, Ormart, Monsalvo-Spencer, Garzón-Favela, ReynosoGranados y Moctezuma, 2008).

Sobre $A$. tuberculosa se han llevado a cabo variadas investigaciones que tratan de manera particular y aislada los aspectos biológicos, productividad y sus atributos comerciales, sin embargo son escasas las que realizan un enfoque holístico y multidisciplinario en vista de sus complejas interacciones dentro del ecosistema de manglar donde se desarrolla.

El objetivo de esta investición es identificar y describir los principales aspectos biológicos, la productividad y los atributos comerciales de $A$. tuberculosa desde una perspectiva integral, en los países donde se ha reportado su presencia, especialmente en Ecuador. 


\section{Metodología}

La metodología aplicada en este estudio teórico fue la revisión bibliográfica de fuentes primarias, secundarias y terciarias. Es una investigación cualitativo-documental de carácter crítico-interpretativa.

\section{Resultados y discusión}

\subsection{Aspectos biológicos}

A continuación se presentan algunas de las características biológicas más resaltantes de $A$. tuberculosa tales como su nombre científico, nombres vulgares, distribución mundial, aspectos morfométricos, ciclo de vida, hábitat preferido y los principales factores ambientales que afectan su desarrollo tales como algunos parámetros físico-químicos-biológicos como la salinidad, temperatura, época del año, textura de suelos del manglar y disponibilidad de nutrientes.

\subsubsection{Nombre científico, nombres vulgares y distribución}

A. tuberculosa (Sowerby 1833) (Arcidae) es un molusco bivalvo (Tabla 1) cuya presencia se ha reportado desde el norte de Perú (Punta Telégrafo), hasta el sur de México (Laguna San Ignacio, Baja California Sur), incluyendo Perú, Ecuador, Colombia, Panamá, Nicaragua, Costa Rica, Guatemala, El Salvador, Honduras y México (Paredes, Cardoso, Santamaría, Esplana y Llaja, 2016).

Este organismo es conocido en cada país con diferentes nombres comunes o vulgares, en Ecuador con el nombre común de "concha prieta" o "concha hembra" (Tabla 2), también se conoce en francés como "arche noire" y en inglés como "pustulose ark o black ark" (Prado-Carpio, Quezada-Abad, Martínez-Soto, Rodríguez-Monroy \& Morris-Díaz, 2018a y Prado-Carpio, Martínez-Soto, Urdaneta de Galué, Morris-Díaz, Rodríguez-Monroy y BorjaHerrera, 2018b).

Tabla 1

Taxonomía de

Anadara tuberculosa

\begin{tabular}{|c|c|}
\hline Phyllum: Mollusca & Clase: Pelecipoda \\
\hline Clase: Bivalvia Linnaeus & Subclase: Autobranchia \\
\hline Orden: Arcoida & Familia: Arcidae \\
\hline Género: Anadara & Especie: tuberculosa \\
\hline
\end{tabular}

Fuente: Elaboración propia basada

en Keen (1971) y Marín Abanto (2013)

Tabla 2

Nombres comunes de

A. tuberculosa en América

\begin{tabular}{|c|c|}
\hline Países & Nombre común \\
\hline Ecuador & Concha prieta, Concha hembra \\
\hline Perú y Nicaragua & Concha negra \\
\hline Salvador y Honduras & Curil \\
\hline Panamá & Chucheca \\
\hline México & Pata de mula \\
\hline Colombia y Costa Rica & Piangua \\
\hline Guatemala & Concha de burro \\
\hline
\end{tabular}

Fuente: Prado-Carpio y otros (2018a)

y Prado-Carpio y otros (2018b) 


\subsubsection{Aspectos morfométricos}

A. tuberculosa posee una concha equivalva, inequilateral, ovalada, gruesa bien sólida, con un contorno ovalado y moderadamente alargada (Figura 1). Su longitud puede variar entre 30 a $70 \mathrm{~mm}$ y el diámetro en un rango de 27 a $48 \mathrm{~mm}$ (alcanzando tallas de $110 \mathrm{~mm}$ ); en la provincia de El Oro, se reporta 43,2 $\mathrm{mm}$ como talla media de los individuos muestreados de $A$. tuberculosa (Instituto Público de Investigación de Acuicultura y Pesca de Ecuador, 2021).

Cuenta con 33 a 37 costillas radiales redondeadas y relativamente juntas; con el margen dorsal algo angulado en ambos extremos. Presenta nódulos o tubérculos sobre las costillas, especialmente sobre el margen anterior. La concha blanca está cubierta por una capa marrón o negra, gruesa denominada perióstraco, fuertemente arrugado, a menudo erosionado en los umbos (Ardila, Navas y Reyes, 2002). Charnela larga, delgada y bastante recta. Bordes internos con fuertes crenulaciones que corresponden a las costillas externas. Concha blanca, con la cavidad umbonal a menudo con un ligero tinte púrpura claro (Keen, 1971; Cantera y Contreras, 1976).

Figura 1

Vista exterior e interior de Anadara tuberculosa mostrando los tubérculos

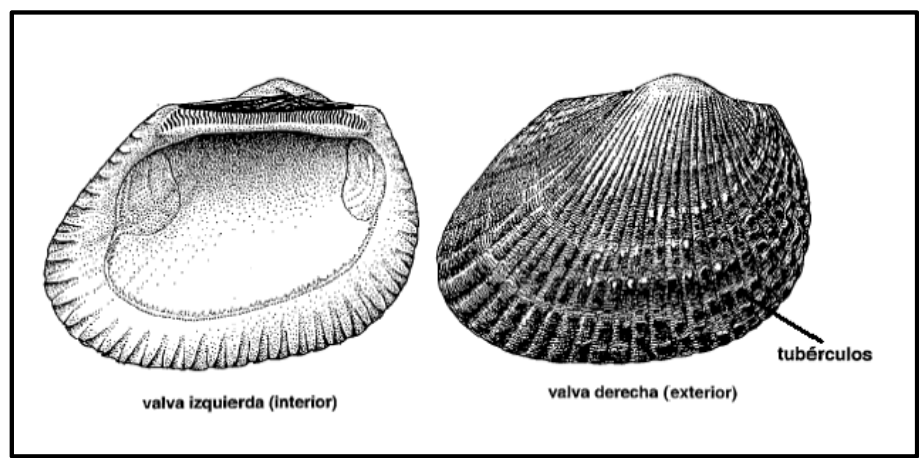

Fuente: Modificado de Fischer, Krupp, Schneider, Sommer, Carpenter y Niem (1995)

Según la Organización de las Naciones Unidas para la Alimentación y Agricultura-FAO (2006), para los bivalvos se emplean los mismos términos anatómicos que se usan para describir estas partes en otros animales, aunque no tengan cabeza ni cola bien definida. El umbo o zona de la charnela, donde se unen las valvas, es la parte dorsal del animal (Figura 2) y la región en el lado opuesto es el margen ventral.

Figura 2

Características internas y externas de las valvas de una concha típica de un molusco bivalvo

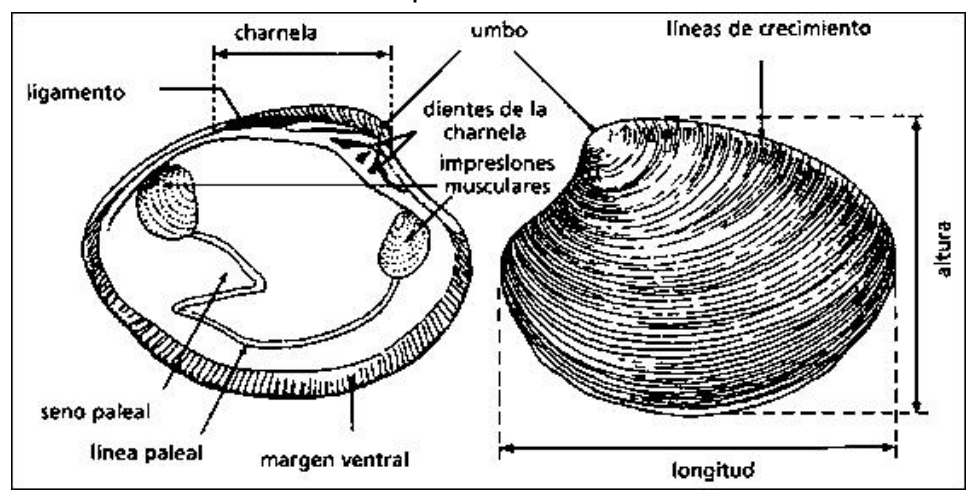

Fuente: Elaboración propia a partir de Cesari y Pellizzato (1990) y FAO (2006). 
En especies que cuentan con sifones (almejas), el pie se encuentra en posición anterior-ventral y los sifones en la zona posterior (Figura 3). En las ostras la zona anterior está en la charnela y en las vieiras, se ubica dónde están localizados la boca y el pie rudimentarios (FAO, 2006).

Al retirar con cuidado una de las valvas de la concha se puede apreciar las partes blandas o pulpa, que representa la parte comercial y comestible de este fruto del mar. Entre las principales partes blandas están: manto, músculo aductor, branquias, pie, sistema digestivo, sistema circulatorio, sistema nervioso y sistema urogenital (FAO, 2006).

Figura 3

Anatomía del tejido blando interno de un molusco bivalvo típico (almeja del género Tapes)

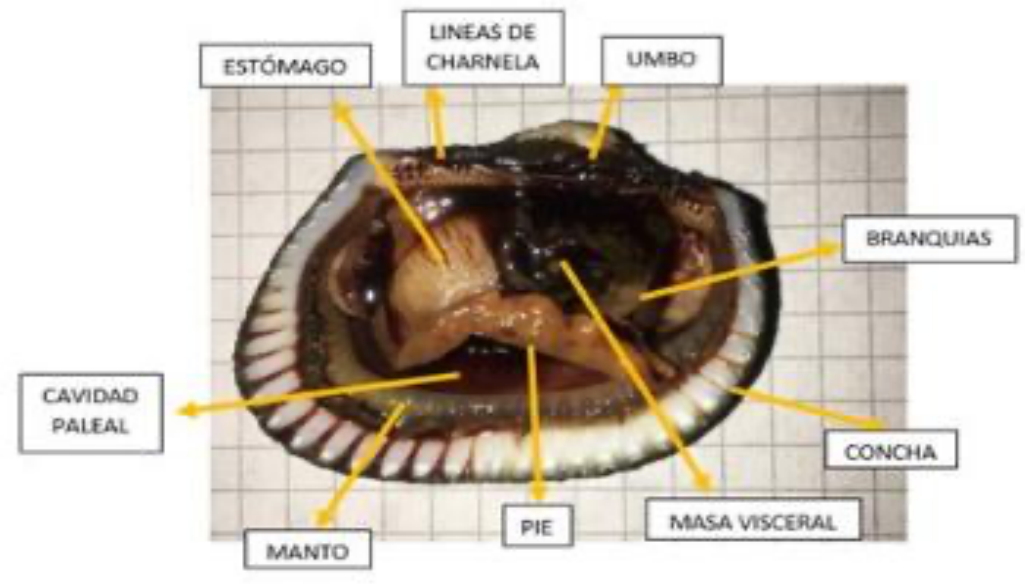

Fuente: Elaboración propia a partir de Cesari y Pellizzato (1990) y FAO (2006)

Los organismos de esta especie son dioicos, los sexos son separados, es decir, hay machos y hembras (Organización del sector pesquero y acuícola del istmo centroamericano - OSPESCA, 2018). Según Cruz (1984), las gónadas están incluidas en la parte supero-lateral de las vísceras rodeando virtualmente al intestino y estómago y están limitadas dorsalmente por los riñones y hepatopáncreas. En individuos maduros el tejido gonadal cubre la parte interna distal del pie y rodea la parte dorsal del cuerpo. El sexo de ejemplares sexualmente maduros y en maduración es fácil de determinar por el color de los productos sexuales, en machos son de color blanquecino y de consistencia pegajosa y los de las hembras son de apariencia granular y de color anaranjado.

Entre los indicadores que permiten su caracterización morfométrica se encuentran: longitud (largo, ancho, y alto), peso de la concha, peso de la carne o pulpa, rendimiento y proporción de sexos (Tabla 3).

Tabla 3

Indicadores morfométricos

de Anadara tuberculosa

\begin{tabular}{|c|c|}
\hline Variable morfométrica & Indicador \\
\hline Largo & $44,9 \mathrm{~mm}$ \\
\hline Ancho & $25,5 \mathrm{~mm}$ \\
\hline Alto & $33,0 \mathrm{~mm}$ \\
\hline Peso total & $26,2 \mathrm{~g}$ \\
\hline Peso fresco & $4,1 \mathrm{~g}$ \\
\hline Rendimiento & $17,2 \%$ \\
\hline Sexo macho & $43,7 \%$ \\
\hline Sexo hembra & $56,3 \%$ \\
\hline
\end{tabular}

Fuente: Elaboración propia basada en Silva

y Bonilla (2001) y Cano- Otalvaro (2011) 
Según Cano (2011), en la costa pacífica colombiana se encontró que individuos de $A$. tuberculosa presentaron valores promedio de peso $30,81 \mathrm{~g}$, longitud $4,49 \mathrm{~cm}$, ancho $2,55 \mathrm{~cm}$ y una altura de $3,30 \mathrm{~cm}$ (Figura 4).

Figura 4

Morfometría para toma

de datos de $A$. tuberculosa
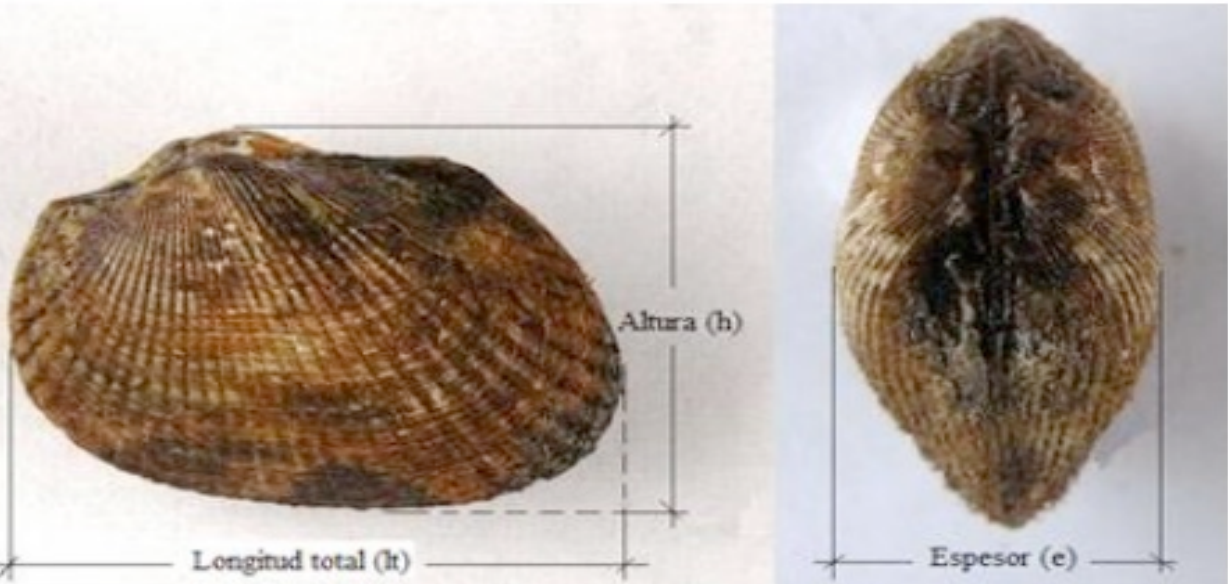

Fuente: Mendoza y Alvitres (2013)

Silva y Bonilla (2001) reportan para organismos localizados en manglar de Purruja, Golfo Dulce, Costa Rica, otras variables morfológicas como son el peso total y peso fresco, que alcanzaron un valor promedio de $26,2 \mathrm{~g}$ y de $4,1 \mathrm{~g}$, respectivamente. El peso fresco está relacionado con la longitud de la concha, mostrando un coeficiente de correlación de 0,81 con longitud estimada de $4,33 \mathrm{~cm}$ y está representado por la masa visceral y gónadas o pulpa, constituida con una apetitosa y nutritiva mezcla de fluidos y músculo de color rojo oscuro.

Los investigadores previamente indicados, encontraron que el valor para la variable rendimiento (peso de la carne / peso total), fue de $17,2 \%$, definida como la capacidad de $A$. tuberculosa para producir la máxima cantidad de carne (Cruz, 1984). Es un índice de condición que funciona como una medida para indicar la calidad del producto que puede tener utilidad económica, también refleja la actividad fisiológica del organismo en diferentes condiciones ambientales (Lucas y Beringer, 1985).

Durante el período de crecimiento de $A$. tuberculosa, la producción de carne aumenta a medida que incrementa su tamaño, sin embargo, a una determinada longitud, la producción cesa, lo que indica crecimiento solamente de la concha por incorporación de carbonato de calcio. Los resultados obtenidos por Silva y Bonilla (2001), indican un aumento en el rendimiento ocurre en las longitudes comprendidas entre 25 y $35 \mathrm{~mm}$.

En cuanto a la variable proporción de sexos, los referidos autores determinaron que el porcentaje promedio de hembras es de $56,3 \%$ y de machos $43,7 \%$, sin mostrar diferencias significativas $(p>0,05)$ en la proporción 1:1.

En otro estudio realizado por Silva-Benavides y Bonilla (2015) en los manglares de Golfito y Playa Blanca de Puerto Jiménez, Golfo Dulce, Costa Rica, se obtuvieron los siguientes resultados para las variables biométricas de A. tuberculosa: longitud $42,51 \mathrm{~mm}$, peso total $36,35 \mathrm{~g}$, peso fresco $8,33 \mathrm{~g}$, rendimiento $23,45 \%$ y proporción de sexos 1:1.

Todos los datos antes presentados, evidencian las similitudes y variaciones morfológicas de $A$. tuberculosa en las diferentes zonas donde se desarrolla. 


\subsubsection{Ciclo de vida}

Entre las características principales del ciclo de vida del género Anadara destacan las siguientes: hábito sedentario, tasa de crecimiento lento, fecundación externa con larva planctónica de vida corta, que luego se fija a un sustrato o conchas adultas y desoves durante todo el año (Broom, 1983; Cruz, 1984; Ishiyama y Terukina, 1987; Instituto Nacional de Pesca y Acuicultura de Colombia- INPA, 1996; Flores, 2002).

Borda y Cruz (2004a) presentan información general sobre el ciclo de vida de A. tuberculosa plasmada en una iconografía, donde se destaca la concatenación espacial y temporal de las fases de vida en esta especie, en un estudio realizado en el Pacífico colombiano (Figura 5). De acuerdo a los autores anteriormente referidos, el ciclo de vida consta de las siguientes etapas: huevo, larva (trocófora, veliger, con umbo, oculada o pediveliger), juvenil y adulto. La reproducción ocurre a la talla de $44 \mathrm{~mm}$ y se puede alcanzar a los 12 meses, a partir de aquí son considerados adultos, y duran 4 años en la pesquería. Se reproduce durante todo el año, pero la época principal de maduración puede variar de una localidad a otra considerando las condiciones ambientales.

Figura 5

Esquema general del ciclo de vida de Anadara tuberculosa

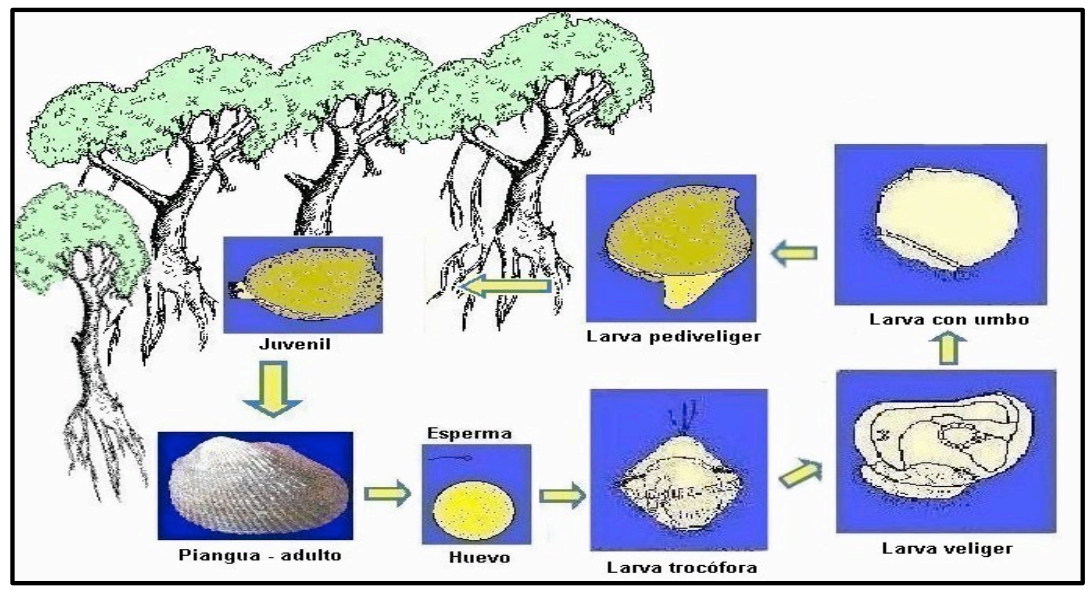

Fuente: Borda y Cruz (2004a)

Nota: Las imágenes de los estadíos no guardan proporción entre sí, a fin de que se pueda observar cada fase

Por su parte, Silva y Bonilla (2001) señalan que en dos sistemas de cultivo en Costa Rica, se alcanzó una longitud promedio de $20 \mathrm{~mm}$ durante el primer año de vida, durante el segundo año el crecimiento se reduce a la mitad del primer año (Villalobos y Báez, 1983), iniciando la madurez sexual entre los 23,2-26,2 mm de longitud (Ampie y Cruz, 1989) y alcanzando su tamaño comercial después de 18-24 meses. Así, se concluye que hay discrepancias en la duración del ciclo de crecimiento, entre uno y dos años, en los diferentes estudios revisados.

Los investigadores García-Domínguez y otros (2008) reportan que el ciclo gonadal de Anadara tuberculosa en Bahía Magdalena, México, se divide en cinco fases: reposo, desarrollo, madurez, emisión de gametos y postemisión de gametos. Estos resultados indican que su reproducción se presenta prácticamente todo el año, aunque con dos períodos masivos de emisión de gametos.

El conocimiento en detalle de los ciclos reproductivos de moluscos de valor comercial tiene gran importancia, ya que ello contribuye a que las pesquerías de estas especies se manejen en forma apropiada (Cruz, 1984). De la información presentada se infiere que se requiere seguir estudiando este tema para conocer mejor el fenómeno del ciclo de vida, fundamentalmente el crecimiento y reproducción de $A$. tuberculosa, para que estos aportes 
sirvan de insumo para implementar las diferentes estrategias ambientales y comerciales relacionadas con este recurso.

\subsubsection{Hábitat y principales factores ambientales que afectan a A. tuberculosa}

Según Mendoza y Alvitres (2013), el hábitat preferido por A. tuberculosa son los sustratos fangosos (arcilloso y limo arcilloso), entre las enmarañadas raíces del manglar, especialmente de Rhizophora mangle y Pelliciera rhizophorae (Mendoza, 2002; Rendón, Suárez y Mejía, 2004; Mendoza y Peralta, 2003). Este ecosistema está expuesto a inundación mareal diaria al bajar la marea muchas de ellas quedan expuestas superficialmente (OSPESCA, 2018).

Mengel y Kirby (1982) han acotado que esta especie también se encuentra asociada a las raíces de $R$. harrisonni, posiblemente por la mejor penetración de agua y oxígeno, disponibilidad de nutrimentos ya que los organismos filtran la materia orgánica para su alimentación (OSPESCA, 2018), o por ser un buen sustrato para la fijación de etapas tempranas de desarrollo de este bivalvo, lo cual podría constituir algún tipo de relación simbiótica.

\section{- Parámetros físico-químicos-biológicos}

Mendoza y Alvitres (2013) reportan los siguientes resultados promedio anuales para los parámetros de calidad del agua en los manglares de Tumbes en Perú: temperatura $28,6^{\circ} \mathrm{C}$; salinidad 28,0 partes por mil (ppt); oxígeno disuelto 4,8 partes por millón (ppm) y pH 7,9. Las concentraciones del ion amonio, nitritos, nitratos y fosfatos presentaron respectivamente valores promedio de: $0,25-0,36-12,38$ y $0,47 \mathrm{ppm}$, en tanto el promedio mensual del fitoplancton fue $814.135 \pm 74.608$ células.litro $^{-1}$.

No obstante, las condiciones físico-químicas, biológicas y la afectación antrópica en los bosques de manglar no son similares en toda la costa pacífica, por tanto, el crecimiento y distribución de $A$. tuberculosa en los variados ecosistemas de manglar no es homogénea, lo que indica que hay factores ambientales que tienen influencia sobre su densidad, disponibilidad y productividad.

A continuación, se describen sucintamente algunas de estas características: salinidad, temperatura, época del año, textura de los suelos, disponibilidad de nutrientes, depredadores naturales, entre otras, que deben ser reconocidos y estudiados en profundidad en el contexto del ecosistema manglar, a fin de diseñar estrategias de conservación y manejo del este recurso.

\section{- Salinidad}

Silva-Benavides y Bonilla-Carrión (2001) reportan que concentraciones elevadas de salinidad favorecen el proceso de reproducción de $A$. tuberculosa, resultado similar a los encontrados por Vega (1994), quien refiere que los máximos de desove se relacionan con altas salinidades.

Campos, Jorge, Foumier y Soto (1990) identificaron lugares en el ecosistema manglar sin presencia de $A$. tuberculosa, cuando las salinidades eran bajas (entre 8-11 ppt), mientras que con salinidades entre 16-29 ppt, si había presencia de la especie y mayores densidades poblacionales. Silva-Benavides y Bonilla-Carrión (2001) coinciden con estos hallazgos al indicar que con salinidades altas (10-34 ppt), existe un mayor número de individuos presentes.

\section{- Temperatura}

Según algunos autores, es uno de los factores que influye en el ciclo reproductivo de los bivalvos. En algunas especies, se ha reportado que el desove se inicia cuando la temperatura excede el nivel crítico característico (Mackie, 1984). Sin embargo, Moreno, Alemán y Bonilla (2019) no encontraron relación clara entre la temperatura del agua y el desove.

García-Domínguez y otros (2008), en una investigación realizada México, reportaron una relación positiva significativa $(r=0,7063, P<0,05)$, entre la temperatura y la fase de madurez de las gónadas, pero no identificaron 
una relación entre la temperatura y la emisión de gametos de $A$. tuberculosa. La temperatura media en el período en estudio fue de $22,8^{\circ} \mathrm{C}$, con un máximo de $29,4^{\circ} \mathrm{C}$ en agosto, para diciembre se obtuvo una medición menor $\left(18,7^{\circ} \mathrm{C}\right)$.

\section{- Época del año}

Es una variable que incluye la temperatura, las precipitaciones (por ende la salinidad del cuerpo de agua), la insolación y otras que influyen sobre el comportamiento de los factores bióticos del ecosistema.

Según Borda y Cruz (2004b), en la Ensenada de Tumaco, Pacífico colombiano, A. tuberculosa se reproduce durante todo el año, pero la época principal de maduración es en noviembre y febrero en función de las condiciones ambientales imperantes de salinidad, temperatura, precipitaciones, entre otras.

Cruz (1984), ha reportado que la gametogénesis se activa cuando hay aumentos en la temperatura y en la salinidad del agua, la época de desove estuvo marcada por las más altas salinidades y temperaturas del agua, observándose que las precipitaciones, contribuyen a diluir la concentración de sales en el manglar

Cada región donde se desarrolla $A$. tuberculosa, tiene condiciones ambientales específicas, a lo largo del año, que deben ser conocidas para establecer la mejor época para su reproducción y extracción, en pro de la preservación del ecosistema manglar y la producción sostenible de este recurso concha.

\section{- Textura de los suelos del manglar}

Silva y Bonilla (2001) realizaron una investigación con relación al tipo de suelo en los manglares, de Costa Rica, concluyendo que el tipo de suelo y la textura son factores importantes para Anadara tuberculosa, ya que es un organismo excavador de fondos lodosos, con hábitat restringido a un substrato suave, tipo arcilloso a limoarcilloso, asociado a las raíces de Rhizophora mangle y $R$. racemosa.

Este molusco bivalvo se ha identificado enterrado y muy rara vez, semienterrado o expuesto, en el sedimento de la zona mesolitoral media interior a profundidades entre 10 a $50 \mathrm{~cm}$ (Sistema de Información sobre Biodiversidad Marina Colombia-SIBM y Instituto de Investigaciones Marinas y Costeras José Benito Vives de Andréis. Colombia -INVEMAR, 2008).

Según Cano (2011), los especímenes de mayor tamaño se encuentran en sedimentos con porcentajes de limos y arcillas inferiores a $50 \%$ (43,26\% a 47,08 \%) y disminuyen su tamaño a medida que aumenta esta relación.

\section{- Disponibilidad de nutrientes}

Según la Enciclopedia Colaborativa de Cuba -EcuRed (2019), A. tuberculosa es un organismo filtrador, participando las branquias, además de su función respiratoria, en la obtención de su alimento (fitoplancton).

El desarrollo de la gónada implica una alta demanda de energía, que procede del alimento ingerido desde el ambiente, de productos de reserva o de ambos. Los períodos de mayor disponibilidad de alimento coinciden con el desarrollo gonadal, también la estacionalidad del desarrollo gonadal está vinculada con el almacenamiento y utilización de reservas acumuladas en el organismo en épocas de abundancia (Mackie, 1984).

García-Domínguez y otros (2008) encontraron una correlación significativa entre la frecuencia de individuos en fase de desarrollo de las gónadas y la disponibilidad de alimento $(r=0,72, P<0,05)$. Señalan que su desarrollo gametogénico depende del alimento ingerido inmediatamente del medio, mientras que el desove es sostenido probablemente por reservas energéticas almacenadas.

Mendoza y Alvitres (2013), reportan que la concentración de fitoplancton relacionada con el crecimiento y supervivencia de $A$. tuberculosa tiene un promedio mensual de 814.135 células.litro $^{-1}$, en un estudio realizado en Perú. 


\section{- Depredadores}

Entre los principales depredadores se han señalado los gasterópodos (Cymatium amictoideum, Natica spp., Thais spp., Bedeva spp.), las aves de pantano, los peces y los cangrejos; así como la nutria (Lutra longicaudus), depredador potencial de moluscos (EcuRed, 2019).

Las variables antes descritas, sobre los aspectos relacionados con el hábitat en el cual se desarrolla $A$. tuberculosa y los factores bióticos y abióticos que influyen sobre su crecimiento y desarrollo, tienen una incidencia directa y en oportunidades contradictoria, sobre la respuesta de dos variables dependientes muy importantes para su productividad, como son la Captura por Unidad de Esfuerzo (CPUE) y la Captura Total o Producción Anual, que se identifican y describen en el siguiente apartado.

\subsection{Aspectos productivos}

Seguidamente, se presentan algunos indicadores que permiten ponderar la productividad del recurso concha con fines comerciales como son la captura, densidad, tasa de crecimiento, mortalidad y supervivencia.

\subsubsection{Captura por Unidad de Esfuerzo}

En la producción pesquera, existen dos indicadores importantes para medir la productividad o situación de la actividad en general, tal es el caso de la Captura por Unidad de Esfuerzo (CPUE) y las Capturas Totales o Producción Anual en una zona geográfica determinada. El concheo o extracción de la concha prieta del manglar es una actividad pesquera que también puede ser evaluada a través de estas dos variables.

Según la FAO (2005), la CPUE se define como la cantidad de pescado capturado (en número o en peso) con una unidad estándar de esfuerzo de pesca: ejemplo, número de peces capturados por una embarcación en un día. La CPUE a menudo se usa como índice de la biomasa (o abundancia) de los peces. Para el caso de la actividad conchera, se conceptualiza como la cantidad de conchas que en promedio un conchero captura del manglar en un día de trabajo (Mora y Moreno, 2009). Este indicador varía de un puerto conchero a otro y de un año a otro, con valores que pueden oscilar entre 95 y 284 conchas capturadas por conchero en un día de pesca, en distintos años en distintos puertos del Ecuador (Tabla 4).

Tabla 4

Captura por Unidad de Esfuerzo (CPUE)

de A. tuberculosa en puertos de Ecuador

\begin{tabular}{|c|c|c|c|}
\hline $\begin{array}{c}\text { Puerto } \\
\text { conchero }\end{array}$ & $\begin{array}{c}\text { CPUE } \\
\text { (conchas/día/pesca) } \\
\text { Año 2004 }\end{array}$ & $\begin{array}{c}\text { CPUE } \\
\text { (conchas/día/pesca) } \\
\text { Año 2009 }\end{array}$ & $\begin{array}{c}\text { CPUE } \\
\text { (conchas/día/pesca) } \\
\text { Año 2020 }\end{array}$ \\
\hline San Lorenzo & 284 & 122 & 120 \\
\hline El Morro /Guayaquil & 196 & Sin información & 172 \\
\hline Hualtaco & 113 & 95 & 200 \\
\hline Puerto Bolívar & 160 & 102 & 170 \\
\hline Muisne & 129 & 105 & 120 \\
\hline Puerto Jelí & 155 & 110 & 150 \\
\hline
\end{tabular}

Fuente: Elaboración propia basada en Mora y Moreno (2009);

Mora- Mora, Moreno y Jurado (2010) y IPIAP (2021)

Se observa una tendencia hacia la disminución de este indicador en los distintos puertos concheros ecuatorianos, entre los años 2004 y 2009. Sin embargo, según los reportes del Instituto Público de Investigación de Acuicultura y Pesca de Ecuador-IPIAP (2021), para el año 2020 se distingue una recuperación en cuanto a número de conchas promedio por día de pesca por conchero en la mayoría de los puertos indicados, más acentuada en puerto Hualtaco, en la provincia de El Oro. Para el puerto de San Lorenzo, provincia de Esmeraldas, se reportan valores 
ligeramente menores en el número de conchas promedio por día de pesca por recolector con 120 (conchas/día/pesca).

El Instituto Público de Investigación de Acuicultura y Pesca de Ecuador-IPIAP (2021) ha señalado que no cuenta con información continúa sobre la captura y esfuerzo del recurso concha, acotando que esta información será procesada cuando se obtengan los datos proveniente de los registros que deben llenar los recolectores de concha de las asociaciones colaboradoras a través del Monitoreo Participativo.

En Colombia, en la ensenada de Tumaco, para los años 1997 y 1998, la CPUE de A. tuberculosa varió entre 196 233 conchas, con media anual de 220 unidades (Portilla- Martínez, Betancourth- Solarte y Arizala- Segura, 1999). Mientras que en Nicaragua, según Lazarich- Gener (2009) el promedio de extracción de conchas por persona se ha estimado en diversos estudios entre 5 y 10 docenas por día. Encuestas realizadas muestran que la extracción promedio diaria podría ser superior a 120 por conchero.

En cuanto a la variable Capturas Totales al año de $A$. tuberculosa, en Ecuador se han alcanzado cifras de 10,7 y 26,0 millones de conchas para los años 2004 a 2008, lo cual es indicativo de lo variable de la cantidad (Mora y otros (2010). Se destaca que no están disponibles datos recientes sobre las capturas por unidad de esfuerzo y capturas totales para el recurso concha.

La sobreexplotación, es uno de los principales problemas de $A$. tuberculosa no solamente en el Ecuador, sino en el resto de países que la producen en la costa del Pacífico americano.

\subsubsection{Densidad}

En condiciones naturales, la densidad poblacional de $A$. tuberculosa ha sido investigada en varios ecosistemas de manglar. En un bosque localizado en Tumbes se han reportado densidades de 0,3 individuos. $\mathrm{m}^{-2}$ (Mendoza, 2002) y de 1,3 individuos. $\mathrm{m}^{-2}$ (Ordinola, Montero, Alemán y Llanos, 2007). Para el manglar de Purruja en Costa Rica, se obtuvo 0,9 individuos. $\mathrm{m}^{-2}$ (Silva y Bonilla, 2001) y para la costa ecuatoriana 1,3 individuos. $\mathrm{m}^{-2}$ (Mora y Moreno, 2010). Estos datos permiten inferir una gran variabilidad en función de la relación existente entre estos organismos y el ecosistema manglar, así como del nivel de extracción al que ha sido sometido como recurso.

En condiciones de cultivo experimental se han alcanzado buenos resultados de producción con densidades de 10 ind. $\mathrm{m}^{-2}$. En este sentido, Silva y Bonilla (2001); Mendoza (2002); Ordinola y otros (2007) y Mora y Moreno (2010), señalan que la densidad de siembra de la semilla de concha, tiene influencia sobre el crecimiento en longitud y peso de estos organismos vivos en proporción inversa a las densidades de siembra, puesto que a mayor densidad de siembra el crecimiento es menor.

Asimismo, se debe tomar en consideración que en condiciones de cautividad prolongada, el estrés causado por el almacenamiento puede alterar notablemente la calidad del producto, especialmente en relación con el índice de engorde, o con el factor de condición, ya que entorpecería el establecimiento de la relación existente entre la madurez y el factor de condición (Rengifo, 1985).

Mendoza y Alvitres (2013) recomienda aplicar la técnica de repoblamiento dirigido para recuperar la densidad de este molusco, logrando su reproducción y asentamiento en laboratorio, hasta un estado de semilla (10 a 15 $\mathrm{mm}$ ), para luego liberarlas en el manglar.

\subsubsection{Tasa de crecimiento}

En un estudio de Mendoza y Alvitres (2013), se evidenció que en corrales ubicados dentro del manglar, con 10 individuos. $\mathrm{m}^{-2}$ de $A$. tuberculosa, se puede obtener un incremento en la longitud de 1,36 $\pm 0,47 \mathrm{~mm}^{\mathrm{mes}}{ }^{-1}$ y peso $0,26 \pm 0,12$ g.mes $^{-1}$, con una supervivencia de 60 a $70 \%$. 
Se ha reportado una velocidad de crecimiento para $A$. tuberculosa de 1,54 mm. $\mathrm{mes}^{-1}$ usando corrales en su medio natural (Quispe, 2003; Mendoza y Peralta, 2003; Malca, 1996). Galdámez y otros (2007) refieren que $A$. tuberculosa puede alcanzar el tamaño comercial en dos años de cultivo, lo cual permite estimar que la tasa de crecimiento es de al menos $1,875 \mathrm{~mm} \cdot \mathrm{mes}^{-1}$, pues también puede llegar a la talla mínima en el lapso de un año.

Mendoza (2013) en Tumbes, Perú, determinó que para Anadara tuberculosa sembrada en su medio natural, en el manglar, a tres densidades con semillas obtenidas en laboratorio en corrales de $2 \mathrm{~m} \times 1 \mathrm{~m}$, el tratamiento t1 (20 ind. $\left./ \mathrm{m}^{-2}\right)$ tuvo el mejor incremento en la longitud y peso $(1,36 \pm 0,47 \mathrm{~mm} / \mathrm{mes}$ y $0,26 \pm 0,12 \mathrm{~g} / \mathrm{mes})$.

\subsubsection{Mortalidad y supervivencia}

Los moluscos bivalvos en el medio natural tienen una alta mortalidad en sus fases juveniles llegando a talla comercial en porcentajes muy bajos (Quispe, 2003). En la investigación desarrollada por Mendoza (2013), indicada anteriormente, se encontró que la supervivencia fue mayor en el tratamiento 1 ( 20 individuos. $\mathrm{m}^{2}$ ) con $60,7 \%$,resultado coincidente con el de Mendoza y Alvitres (2013) donde se evidenció que en corrales ubicados dentro del manglar, con 20 individuos. $\mathrm{m}^{-2}$, se puede alcanzar con una supervivencia de 60 a $70 \%$. Por su parte, Samaniego (2008) reporta que el cultivo en canastas presentó una supervivencia de $85 \%$.

Con base a todos los datos antes expuestos, se infiere que es necesario profundizar en los estudios sobre los requerimientos nutricionales y ambientales de $A$. tuberculosa, con la finalidad de establecer un mejor plan de manejo (Robles-Mungaray y otros, 1999). La preservación del manglar, la extracción en condiciones naturales, el cultivo y manejo acuícola de $A$. tuberculosa para ser alcanzado de manera sostenible, amerita el desarrollo de procesos permanentes de investigación y desarrollo en todas las áreas.

\subsection{Atributos comerciales y de calidad}

Las características comerciales y de calidad de $A$. tuberculosa, están relacionados con aquellos aspectos que la convierten en un producto demandado y apetecido en la cocina del hogar, restaurantes, picanterías y cevicherías en las poblaciones costeras del Ecuador y demás países que la producen. Está considerada como un manjar afrodisíaco, con importante demanda local en restaurantes y sitios turísticos, donde se sirve fresca (cruda) en cocteles, frita, asada o hervida y enlatada industrialmente; también cantidades considerables son exportadas intra-regionalmente (OSPESCA, 2018).

En el Ecuador, por ejemplo, se ofrecen a los comensales los siguientes platos: ceviche de concha, arroz con concha, sopa de concha, sudado de concha, asado de concha, meloso de concha, sango de concha, concha al ajillo, mixto con concha, encocado de concha, concha frita, coctel de concha, entre otros exquisitos platos. Por tanto, el producto debe conservar atributos comerciales propios de los alimentos que se consumen predominantemente frescos o crudos: calidad física y organoléptica, calidad nutricional y calidad sanitaria.

\subsubsection{Calidad física y organoléptica}

La calidad física y organoléptica hace referencia a los atributos de los alimentos que pueden ser percibidos a través de los sentidos, relacionados con los aspectos físicos y considerando el aspecto visual de apariencia, integridad, color y talla o tamaño del producto, así como también las características organolépticas tales como el sabor, olor y otros relacionados. De todos estos atributos, desde el punto de vista productivo los más relevantes son la talla y la frescura.

\section{- Talla}

Los consumidores de concha las prefieren de tamaño grande, sin embargo, con relación al tamaño relativo, no se ha encontrado en la revisión bibliográfica realizada, una referencia definida sobre a los tamaños grande, 
mediano y pequeño, rango de longitud o su peso. Aun cuando, investigadores como Espinosa, DelgadoHernández, Orobio-Riofrío, Mejía-Ladino y Gil-Agudelo (2010) reportan en Colombia, tamaños mínimos de 1,6 $\mathrm{cm}$ con promedios de $4,4 \mathrm{~cm}$ y máximo de $7,8 \mathrm{~cm}$.

En este sentido, ante la ausencia de una referencia cuantitativa documentada para la determinación del tamaño de $A$. tuberculosa, se considera necesario utilizar como referencia, la talla mínima de extracción, que se ha establecido en las normas técnicas para efectos de conservación del recurso desde el punto de vista ambiental, pero que también, puede servir de estándar para el establecimiento de los atributos de calidad física por la talla del producto concha prieta.

Por tanto, tal como fue referido en el apartado de ciclo de crecimiento de $A$. tuberculosa, el desove empieza con una talla de $30 \mathrm{~mm}$ y alcanza su madurez con una talla media de madurez (TMM) de $44 \mathrm{~mm}$. Ahora bien, la talla comercial a la cual debe ser extraída, ha sido sugerida en investigaciones y regulada en las legislaciones de distintos países. Pero, finalmente es el mercado, quien le otorga esos atributos deseables, en este caso la talla y apariencia, pues los consumidores prefieren la concha prieta lo más fresca y grande posible.

En una investigación realizada Borda y Portilla (1998) en Colombia, se reseña que se estableció la Talla Mínima de Captura (TMC) en $50 \mathrm{~mm}$ de Anadara tuberculosa (piangua). Esta recomendación fue acogida por la Autoridad Nacional de Acuicultura y Pesca de Colombia-AUNAP y Universidad de Magdalena, Colombia(2013), organismos que establecieron que la TMM es a los $51 \mathrm{~mm}$, la TMC de 48,98 mm y la talla legal de captura de $50 \mathrm{~mm}$, para la extracción comercial de A. tuberculosa, según Resolución 0539 de 2000 del Instituto Nacional de Pesca y Acuicultura de Colombia- INPA).

En Perú, el Ministerio de Pesquería publicó la Resolución Ministerial № 209-2001-PE, de fecha 26 de junio de 2001, aprobando la relación de tallas mínimas de captura y tolerancia máxima de ejemplares juveniles de principales peces marinos e invertebrados, incluyendo a $A$. tuberculosa con una talla de $4,5 \mathrm{~cm}$.

El Ministerio de Acuacultura y Pesca de Ecuador (2005), publicó el Acuerdo Ministerial № 005, relativo al tamaño mínimo de extracción y comercialización de la concha prieta, estableciendo una longitud de 4,5 cm, medida desde el lado anterior al lado posterior de las valvas.

Los tamaños mínimos establecidos para la extracción y comercialización de $A$. tuberculosa en las normas legales presentadas, sirven como referencia para inferir que el tamaño mínimo comercial que presenta mayor demanda por parte de los consumidores de concha prieta es de $45 \mathrm{~mm}$ y un tamaño deseable es de $50 \mathrm{~mm}$, mientras que los tamaños menores a $45 \mathrm{~mm}$, pueden ser considerados como pequeños.

Otros atributos físicos se relacionan con la integridad del producto, principalmente sin irregularidades (Maldonado, 2018) y que presente el color característico que le da su nombre "concha negra o prieta".

\section{- Frescura}

El investigador señalado previamente, refiere que el producto debe tener un olor fresco, su sangre (los órganos y fluidos internos de la concha que son liberados al abrirla) de color negro brillante, de consistencia firme y sus gónadas bien sujetas a sus valvas.

En cuanto a su frescura, se debe indicar que las conchas son extraídas y comercializadas vivas y solo son abiertas, al momento que van a ser consumidas frescas o cuando vayan a ser procesadas. Por tanto, con relación al consumo fresco, que es el más demandado en la costa del Ecuador. Maldonado (2018) señala que se deben descartar las conchas moribundas, es decir, aquellas que son incapaces de sellarse herméticamente a cualquier estímulo, su olor no debe ser nauseabundo, su color debe ser negro vivo, no opaco o verdoso. 
Un dato importante, es el tiempo que el organismo puede mantenerse vivo, luego que es extraído de su hábitat natural y bajo qué condiciones y técnicas de manipulación. Aquí el atributo deseable es que permanezca vivo el mayor número de días posible.

\subsubsection{Calidad nutricional}

La composición bioquímica, tanto proximal como en nutrientes esenciales, depende de las condiciones ambientales en que se encuentran creciendo los bivalvos, y por ello presenta variaciones estacionales (Urrutia, Navarro, Clasing \& Stead, 2001), geográficas y con la profundidad, así como con las diferentes etapas de desarrollo, y con las variaciones en el manejo y la dieta.

Una investigación realizada en Costa Rica determinó la composición proximal en base seca de $A$. tuberculosa, con niveles de proteína de $61,6 \%$, carbohidratos $21,6 \%$; cenizas, 8,8\%, lípidos 7,9\%, valor calórico de 5,2 kcal/g., características que lo ubican como un alimento recomendado para el consumo humano, por su bajo contenido de grasa y su alto contenido proteico y energético (Cruz, Fonseca-Rodríguez y Chavarría-Solera, 2012).

Además, en el imaginario popular, a la concha prieta se le otorgan propiedades afrodisiacas, que son propias de los diferentes frutos del mar, pero que en este caso alcanza una categoría superior o especial.

\subsubsection{Calidad sanitaria e inocuidad}

En los últimos años, con el incremento del comercio internacional de los recursos biológicos marinos y continentales, los gobiernos, las empresas y las organizaciones de consumidores, han puesto el foco en la afectación (Martínez, Rodríguez-Calleja, Santos, Otero \& García-López, 2009; Hara-Kudo y Kumagai, 2014), del medio acuático, ya que puede representar un riesgo directo ante la contaminación microbiana, así como la química por el uso desmedido de fertilizantes, pesticidas agrícolas, derrames de petroleros, efluentes domésticos e industriales que descargan en zonas costeras (Herrero, Palacios, Laya y Vega, 1999).

En relación a los moluscos bivalvos tiene gran importancia su inocuidad, pues estas especies se alimentan por mecanismos de filtración no selectiva y como consecuencia, se pueden convertir en concentradores de algunas sustancias contaminantes (arenillas, metales pesados, hidrocarburos, compuestos derivados de pesticidas, entre otros) y de diversos patógenos, entre los que se encuentran bacterias, virus y ciertas toxinas producidas por microalgas, que constituyen un riesgo potencial para la salud del consumidor (Sandoval y Saborío, 2008).

Los moluscos bivalvos son muy comercializados y consumidos a nivel internacional, por tanto, al igual que cualquier otro producto de consumo alimentario, deben cumplir con algunas normas de calidad sanitaria y de inocuidad, entre las cuales destacan (Reglamento (CE) No 1881/2006 de la Comisión de las Comunidades Europeas. Contenido máximo de determinados contaminantes en los productos alimenticios, 2006): características visuales relacionadas con el estado vivo y la frescura, como son:

- Conchas sin suciedad

- Una respuesta adecuada a la percusión y cantidades normales de líquido intravalvar

- Contener menos de 300 coliformes fecales, o menos de $230 \mathrm{E}$. coli, por $100 \mathrm{~g}$ de carne y líquido intravalvar

- No contener Salmonella en $25 \mathrm{~g}$ de carne ni compuestos tóxicos u objetables

- Límite superior en cuanto al contenido de radionucleidos no debe sobrepasar los límites establecidos para los productos alimenticios

- En las partes comestibles de los moluscos, el contenido total de toxina paralizante del marisco (PSP) no debe sobrepasar $80 \mu$ por $100 \mathrm{~g}$. 
- Los métodos de ensayo biológicos habituales no deben dar un resultado positivo a la presencia de la toxina diarreica del marisco (DSP) en las partes comestibles de los moluscos

- En ausencia de procedimientos de ensayo rutinarios para virus y de valores virológico de referencia, los controles sanitarios deben estar basados en recuentos de bacterias fecales.

En vista que las aguas costeras están sometidas a diferentes fuentes de contaminación, de origen doméstico, agrícola, industrial y pesquero propiamente dicho, se hace complicado controlar la contaminación potencial que puedan sufrir los moluscos bivalvos en general y $A$. tuberculosa en particular. Sólo sería posible a través de la prevención y control de las fuentes de intervención.

La forma de consumo preferida de los moluscos bivalvos es en crudo, de ahí el riesgo asociado a la contaminación microbiana a los consumidores por falta de seguridad sanitaria. Por tal motivo, es necesario gestionar de manera integral el problema de esta afectación, mediante el análisis del grado de contaminación en los organismos acuáticos, para determinar procedimientos prácticos de remediación que permitan erradicar la presencia de microorganismos patógenos.

Según Lazarich-Gener (2009), el proceso de depuración exige la construcción de tanques donde se sumergen las conchas en agua no contaminada o sustancias depuradoras, si se quiere acelerar la depuración. El proceso puede realizarse de manera artesanal con el uso de ácido acético como depurador. La depuración se produciría en 24 a 72 horas mediante el proceso de alimentación por filtrado característico de los bivalvos, eliminando sustancias adquiridas en aguas contaminadas. C. Hernández citado por Lazarich Gener (2009), Universidad Nacional Autónoma de Nicaragua- UNAN, ha realizado estimaciones sobre el coste variable unitario de la depuración artesanal (sin tener en cuenta los costes fijos de la inversión inicial, ni otros costes de mantenimiento de la depuradora), que ascendería a 0,03 US\$ por docena.

La situación relativa a la calidad sanitaria que presenta $A$. tuberculosa, podría convertirse en un problema importante para su comercialización intra-regional actual y futura, si los gobiernos de los países latinoamericanos de la costa del Pacífico aplicaran de manera rigurosa, sus normativas sanitarias vigentes y además, sería una limitante, para la potencial comercialización del producto hacia los Estados Unidos y España. Estas naciones cuentan con grandes grupos de emigrantes de los países productores de $A$. tuberculosa, que podrían estar interesados en consumir este apetecido producto endémico de su tierra de origen.

\section{Conclusiones}

Los aspectos biológicos, productividad y los atributos comerciales de $A$. tuberculosa guardan una relación estrecha y de interdependencia, que debe ser mantenida y desarrollada para alcanzar la conservación del recurso y su producción sostenible en armonía con el ecosistema manglar.

En los aspectos biológicos, destacan los indicadores morfométricos, tales como: el largo, ancho, alto, peso total, peso fresco, rendimiento y la proporción de sexo macho y sexo hembra. Siendo el largo, el principal indicador con valor mínimo de explotación comercial de $4,5 \mathrm{~cm}$. Por otra parte, con relación al ciclo de vida y edad a la cual este molusco debería ser extraído, existe un rango de tiempo de 12 a 24 meses, en función a la velocidad de crecimiento del espécimen, de las condiciones ambientales y de manejo.

La actividad biológica de $A$. tuberculosa está íntimamente relacionada al bosque de manglar y todas las interacciones existentes en este ecosistema complejo, siendo los principales factores ambientales que afectan su crecimiento desarrollo y productividad: temperatura, salinidad, época del año, textura de los suelos del manglar, disponibilidad de nutrientes, distintas variables físico-químicas y sus depredadores naturales. 
Los aspectos productivos están relacionados a la Captura por Unidad de Esfuerzo (CPUE) y las Capturas Totales o Producción Anual en una zona geográfica determinada, como principales variables productivas y como indicadores, la densidad de conchas, tasa de crecimiento,mortalidad y supervivencia, los cuales tienen amplia influencia sobre las variables productivas.

Los atributos comerciales de $A$. tuberculosa tienen relación con la calidad física y organoléptica, en particular su talla y frescura, así como también con su calidad sanitaria e inocuidad, en correspondencia con su naturaleza alimenticia de organismo filtrador.

Se recomienda:

Profundizar en el estudio del ciclo de vida y velocidad de crecimiento de $A$. tuberculosa, específicamente, en los factores que pueden acelerar este proceso.

Ampliar el conocimiento sobre técnicas acuícolas de baja intensidad en armonía con el manglar, que tiendan a incrementar la densidad de especímenes por superficie.

Aplicar estrategias de buenas prácticas de producción y de manejo sanitario e inocuidad, extendidas a los procesos de comercialización y elaboración de platos a nivel de restaurantes y hogares.

Explorar los mercados internacionales en Europa y Estados Unidos, para impulsar un proceso de exportación, que cumpla con las normativas técnicas y legales vigentes.

\section{Referencias bibliográficas}

Ampie, C., y Cruz, R. A. (1989). Tamaño y madurez sexual de Anadara tuberculosa (Bivalvia: Arcidae) en Costa Rica. Brenesia, 31, 21-24.

Ardila, N.G., Navas, Y., y Reyes, J. (2002). Libro rojo de invertebrados marinos de Colombia. Serie Libros Rojos de Especies Amenazadas de Colombia. Instituto de Investigación de Recursos Biológicos Alexander Von Humboldt y Ministerio del Medio Ambiente. Bogotá, Colombia. 136 pp.

Arriga, M.L., y Martínez, O. J. (2003). Plan de ordenamiento de la pesca y acuicultura del Ecuador. Subsecretaría de Recursos Pesqueros. Recuperado de www.oa.upm.es/id/file/257721. Consulta 30.04.19.

Autoridad Nacional de Acuicultura y Pesca de Colombia- AUNAP y Universidad del Magdalena de ColombiaUNIMAGDALENA. (2013). Tallas mínimas de captura para el aprovechamiento sostenible de las principales especies de peces, crustáceos y moluscos comerciales de Colombia. Convenio 058 de 2013 entre la Autoridad Nacional de Acuicultura y Pesca y la Universidad del Magdalena. 58 pp.

Borda, C. A., y Cruz, R. (2004a). Reproducción y reclutamiento del molusco Anadara tuberculosa (Sowerby, 1833) en el Pacífico colombiano. Rev. Invest. Mar, 25(3),185-195.

Borda, C. A., y Cruz. R. (2004b). Crecimiento y tasas de mortalidad del bivalvo Anadara tuberculosa (Sowerby 1833) en el Pacífico colombiano. Rev. Invest. Mar, 25(3), 177-184.

Borda, R., Carlos, A., y Portilla, E. G. (1998). Talla de captura, madurez sexual, comercialización y recomendaciones para el manejo de la Anadara tuberculosa (Piangua hembra) en la ensenada de Tumaco (Nariño) Pacífico colombiano. Recuperado de https://www.academia.edu/.../TALLA_DE_CAPTURA_MADUREZ_SEXUAL_COME.. Consulta 07.05.19. 
Broom, M.J. (1983). Gonad development and spawning in Anadara granosa (L) (Bivalvia:Arcidae). Aquaculture, $30,211-219$.

Campos, M., Jorge, A., Foumier, M. L., y Soto, R. (1990). Estimación de la población de Anadara tuberculosa (Bivalvia: Arcidae) en Sierpe-Térraba, Costa Rica. Rev. Biol. Trop., 38(2B), 477-480.

Cano- Otalvaro, J. L. (2011). Caracterización morfométrica de Anadara tuberculosa y A. similis en la costa pacífica colombiana. Programa Académico de Biología. Trabajo de grado. Universidad del Valle. Facultad de Ciencias Naturales y Exactas. Colombia. Recuperado de www. bibliotecadigital.univalle.edu.co/bitstream/10893/3904/4/CB-0438843.pdf. Consulta 02.05.19.

Cantera, J., y Contreras, R. (1976). Informe preliminar sobre el potencial malacológico aprovechable en el Pacífico colombiano. En: Memorias Seminario sobre el océano Pacífico sudamericano. Cali, Colombia. $p$ 440-499.

Cesari, P., \& Pellizzato, M. (1990). Biology of Tapes Philippinarum, p 21-46. In: Tapes Philippinarum: Biologia e Sperimentazione. Regione Veneto, Ente di Sviluppo Agricolo, Venice: 299 pp. (text in Italian and English)

Cruz, R. (1984). Algunos aspectos de la reproducción en Anadara tuberculosa (Pelecypoda: Arcidae) de Punta Morales, Puntarenas, Costa Rica. Rev. Biol. Trop., 32, 45-50.

Cruz, R. A., Fonseca-Rodríguez, C., y Chavarría-Solera, F. (2012). Comparación de la composición química proximal de la carne de Anadara Tuberculosa y A. Similis (Bivalvia: Arcidae) de Chomes, Puntarenas, Costa Rica. Rev. Mar. Cost., 4(1), 95-103.

Comisión de las Comunidades Europeas. (2006). Reglamento (CE) No 1881/2006 de la Contenido máximo de determinados contaminantes en los productos alimenticios. Diario Oficial de la Unión Europea.

Recuperado de http://eur-lex.europa.eu/legal-content/ES/TXT/PDF/?uri=CELEX:32006R1881\&from=ES. Consulta 04.01.2018.

ECURED-Enciclopedia Colaborativa Cubana . (2019). Anadara tuberculosa. Recuperado de https://www.ecured.cu/Anadara_tuberculosa. Consulta 04.05.19.

Espinosa, S., Delgado-Hernández, M.F., Orobio Riofrío, B., Mejía-Ladino, L.M., y Gil-Agudelo, D.L. (2010). Estado de la población y valoración de algunas estrategias de conservación del recurso piangua Andara tuberculosa (Sowerby) en sectores de Bazán y Nerete, costa pacífica nariñense de Colombia. Bol. Invest. Mar. Cost., 39 (1), 161-176. ISSN 0122-9761.

FAO- Organización de las Naciones Unidas para la Alimentación y Agricultura (2005). Guía del administrador pesquero. Editado por Kevern L. Cochrane. Recuperado de http://www.fao.org/3/y3427s/y3427s0d.htm. Consulta 07.05.19. ISBN 92-5-304773-9.

FAO - Organización de las Naciones Unidas para la Alimentación y Agricultura (2006). Cultivo de bivalvos en criadero. Un manual práctico. Recuperado de http://www.fao.org/docrep/009/y5720s/y5720s04.htm\#bm04. Consulta 09.12.2018.

Fischer, W., Krupp, F., Schneider, W., Sommer, C., Carpenter, K. E., y Niem, V. (1995). Guía FAO para la identificación de especies para los fines de la pesca Pacífico centro-oriental plantas e invertebrados. Roma, FAO Vol I. Recuperado de http://www.fao.org/3/t0851s/t0851s00.htm\#Contents. Consulta 26.10.2019. 
Flores, L. (2002). Biometría, edad y crecimiento de Anadara tuberculosa (C.B. Adams,1852) y Anadara similis (Sowerby, 1833) en Estero Hondo, Reserva Ecológica Manglares Cayapas-Mataje (REMACAM), Esmeraldas. Tesis de Biólogo. Universidad de Guayaquil, Ecuador. 99 pp.

Galdámez, A., Pacheco, P., Pérez, I., y Kino, S. (2007). Guía para la producción de Anadara spp. 2006-2007: Producción artificial de semillas, cultivo intermedio y cultivo de $A$. tuberculosa y A. grandis. Proyecto JICACENDEPESCA. CENDEPESCA/Ministerio de Agricultura y Ganadería (MAG). El Salvador. 42 pp.

García-Domínguez, F. A., Haro-Hernández, D.E., García-Cuellar, A., Villalejo-Fuerte, A., y Rodríguez-Astudillo, S. (2008). Ciclo reproductivo de Anadara tuberculosa (Sowerby, 1833) (Arcidae) en Bahía Magdalena, México. Revista de Biología Marina y Oceanografía, 43(1), 143-152. Recuperado de https://dx.doi.org/10.4067/S0718-19572008000100015. Consulta 26.10.2019.

Hara-Kudo, Y., \& Kumagai, S. (2014). Impact of seafood regulations for Vibrio parahaemolyticus infection and verification by analyses of seafood contamination and infection. Epidemiology and Infection, 142(11), 2237-2247. Recuperado de 26.10.2019. doi:10.1017/S0950268814001897.

Herrero, U., Palacios, F., Laya, H., y Vega, A. (1999). Ausencia de detección de enterovirus en bivalvos Anadara tuberculosa (Bivalvia: Arcidae) por contaminación química en el Pacífico de Costa Rica. Rev. Biol. Trop., 47 (3), 419-27.

INPA- Instituto Nacional de Pesca y Acuicultura de Colombia (1996). Evaluación del potencial de semilla de bivalvos comerciales en el Pacífico colombiano. Informe Técnico Final. Colombia, Buenaventura, 45 pp.

IPIAP- Instituto Público de Investigación de Acuicultura y Pesca de Ecuador (2021). Investigación de los Recursos Bioacuáticos y su Ambiente. Programa Concha-Cangrejo. FEBRERO 2021. Recurso Concha (Anadara tuberculosa y Anadara similis) en la provincia de El Oro. Recuperado de http://www.institutopesca.gob.ec/wp-content/uploads/2018/01/REPORTE-WEB-CONCHA-FEBRERO2021.pdf. Consulta 06.04.2021.

Ishiyama, V., y Terukina, S. (1987). Reproducción en Anadara tuberculosa y Anadara similis de la zona de Puerto Pizarro, Perú. Rev. Biota, XIV (95), 2-11.

Keen, A. M. (1971). Sea shells of tropical West America. Stanford. Stanford Univ. Press. 1064 pp.

Lazarich- Gener, R. (2009). Estudio de mercado de la concha negra (Anadara similis y Anadara tuberculosa) en Nicaragua. Comercialización con garantía de inocuidad. Recuperado de http://www.bvsde.org.ni/Web_textos/GOLFONSECA/CIDEA/0002/2009 Estudio mercado final de mouscos.pdf. Consulta 26.10.2019.

Lucas, A., \& Beringer, P. (1 March 1985). The use of physiological condition indices in marine bivalve aquaculture. Aquaculture, 44(3), 187-200.

Mackenzie, J. R., \& Clyde L. (2001). The fisheries for mangrove cockles, Anadara spp., from Mexico to Peru, with descriptions of their habitats and biology, the fishermen's lives, and the effects of shrimp farming. Marine Fisheries Review, 63(1), 1-39.

Mackie, G. L. (1984). Bivalves. En: Tompa AS, NH Verdonk \& J Van Der Biggelaar (eds), The Mollusca: Reproduction 7: 351-418. New York, Academic Press.

Malca, C. (1996). Aportes para un manejo sostenible de los manglares de Tumbes: engorde de conchas negras Anadara tuberculosa en los manglares de Tumbes. Tumbes, Perú. Pro Naturaleza. 
Maldonado, J. E. (2018). Aplicación de la concha prieta ecuatoriana en la alta cocina. Proyecto de titulaciónen Gastronomia. Facultad de Turismo, Hospitalidad y Gastronomía, Universidad de las Américas, 67 p. Recuperado de http://dspace.udla.edu.ec/handle/33000/8620. Consulta 08.05.19.

Marín-Abanto, P. M. (2013). Evaluación de concha negra (Anadara tuberculosa y Anadara similis) en los manglares de puerto Pizarro, Tumbes - Perú, mediante un modelo de biomasa dinámica. Tesis para optar el título de Biólogo con mención en Hidrobiología y Pesquería. Facultad de Ciencias Biológicas, Unidad de Post-Grado, Universidad Nacional Mayor de San Marcos. Lima - Perú. 67 pp.

Martínez, O., Rodríguez-Calleja, J. M., Santos, J.A., Otero, A., \& García-López, M. I. (2009). Foodborne and indicator bacteria in farmed molluscan shellfish before and after depuration. J Food Prot., 72(7), 14431449. doi.org/10.4315/0362-028X-72.7.1443.

Mazón-Suástegui, J., Robles-Mungaray, M., Ormart, P., Monsalvo-Spencer, P., Garzón-Favela, J., ReynosoGranados, T., y Moctezuma, T. (2008). Reproducción controlada de tres especies de concha negra Anadara spp. en el laboratorio. Universidad Nacional Autónoma de Nicaragua - UNAN. Facultad de Ciencia y Tecnología; Departamento de Biología. Segundo Encuentro Conchero León, Nicaragua.

Mendoza- Neyra, O. A. (2013). Efecto de la densidad de siembra sobre el crecimiento y supervivencia de Anadara tuberculosa (Sowerby, 1833) con semillas obtenidas en laboratorio. Tesis para optar el Grado de Doctor en Ciencias Ambientales. Universidad Nacional de Trujillo.Perú.

Mendoza, N. O., y Alvitres, V. (2013). Crecimiento y supervivencia de Anadara tuberculosa (Sowerby, 1833) a tres densidades. Universidad Nacional de Tumbes, Perú. Revista de Investigación Científica Manglar, $12(1), 55-64$.

Mendoza, O. (2002). Estructura por tallas, densidad poblacional y relación peso longitud de Anadara tuberculosa (Sowerby, 1833) en los manglares de Puerto Pizarro y Zaru milla-Tumbes. Trabajo de investigación docente. Univ. Nac. de Tumbes, Perú.

Mendoza, O., y Peralta, Y. T. (2003). Crianza de Anadara tuberculosa (Sowerby, 1833) haciendo uso de corrales, en su medio natural. Rev. Manglar, 1(1),77-85.

Mengel, K., \& Kirkby, E. A. (1982). Principles of plant nutrition. International Potash Institute, 3a. ed., Suiza. $450 \mathrm{pp}$.

Ministerio de Acuacultura y Pesca de Ecuador. (2005). Tamaño mínimo de extracción y comercialización de la concha prieta. Acuerdo Ministerial № 005 (Concha). Acuerdos ministeriales. Recuperado de http://www.acuaculturaypesca.gob.ec/subpesca93-acuerdo-ministerial-n-005concha.html. Consulta 09.12.2018.

Ministerio de Pesquería del Perú. (2001). Tallas mínimas de captura y tolerancia máxima de ejemplares juveniles de principales peces marinos e invertebrados. Resolucion Ministerial № 209-2001-PE. Recuperado de https://tarwi.lamolina.edu.pe/licochea/pesca/tallas/rm209-2001-pe.doc. Consulta 07.05.19

Mora, E., y Moreno, J. (2009). La pesquería artesanal del recurso concha (Anadara tuberculosa y A. similis) en la costa ecuatoriana durante el año 2004. Boletín Científico y Técnico, 20(1), 1-16. 
Mora, E., y Moreno, J. (2010). Abundancia y estructura poblacional de Anadara tuberculosa y Anadara similis en las principales áreas de extracción de la costa ecuatoriana. Instituto Nacional de Pesca. Investigación de los Recursos Bioacuáticos y su Ambiente. pp 18.

Mora, E., Moreno, J., y Jurado, Y. V. (2010). Pesqueria de la concha prieta (Anadara tuberculosa y Anadara similis) en el 2009: indicadores pesqueros y condicion reproductiva en la zona sur y norte de Ecuador. Recuperado de https://www.oceandocs.org/handle/1834/4795?show=full. Consulta 09.12.2018.

Moreno, J., Alemán,C., y Bonilla, R. (2019). Aspectos biométricos y reproductivos de Anadara tuberculosa (Sowerby, 1833) (Bivalvia: Arcidae) en dos sitios de extracción de Esmeraldas y El Oro, Ecuador. Rev. Mar. Cost., 11 (2), 31-43, julio-diciembre 2019. DOI: http://dx.doi.org/10.15359/revmar.11-2.2. ISSN: 1659$455 \mathrm{X}$.

Ordinola, E., Montero, P., Alemán, S., y Llanos, J. (2007). Prospección del recurso concha negra (Anadara tuberculosa) en los manglares de Tumbes. IMARPE-Tumbes. Lima, Perú.

OSPESCA- ORGANIZACIÓN DEL SECTOR PESQUERO Y ACUÍCOLA DEL ISTMO CENTROAMERICANO (2018). Anadara tuberculosa. Recuperado de http://climapesca.org/2018/09/06/anadara-tuberculosa/. Consulta 03.05.2019.

Paredes, C., Cardoso, F., Santamaría, J., Esplana, J., y Llaja, L. (2016). Lista anotada de los bivalvos marinos del Perú. Revista Peruana de Biología. 23(2), 127-150. Recuperado de https://dx.doi.org/10.15381/rpb.v23i2.12397. Consulta 26.10.2019.

Portilla-Martinez, E., Betancourth- Solarte, V., y Arizala- Segura, I. A. (1999). Evaluación de algunos aspectos pesqueros y estado de explotacion de la piangua (Anadara tuberculosa (Sowerby,1833) y Anadara similis (c.Adams, 1852) en el municipio de Tumaco. Programa Ingenieria en Produccion Acuicola. Universidad de Nariño, Facultad de Ciencias Pecuarias. Recuperado de www. siam.invemar.org.co/download-alfrescofile/131636. Consulta 07.05.2019.

Prado-Carpio, E., Quezada-Abad, C., Martínez-Soto, M., Rodríguez-Monroy, C., \& Morris-Díaz, A. (2018a). An approximation to agribusiness development in the value chain of the bivalve mollusk Anadara tuberculosa (Sowerby, 1833)(Arcidae). Proceedings in Food System Dynamics, 382-393. Recuperado de http://centmapress.ilb.uni-bonn.de/ojs/index.php/proceedings/article/view/1831. Consulta 07.10.2019.

Prado-Carpio, E., Martínez-Soto, M. E., Urdaneta de Galué, F., Morris-Díaz, A., Rodríguez-Monroy, C., y BorjaHerrera, A. (2018b). Modelo teórico de relaciones entre la gestión de agronegocios y el desempeño de la cadena de valor de la concha prieta Anadara tuberculosa. Recuperado de http://www.laccei.org/LACCEI2018-Lima/meta/FP396.html. Consulta 04.06.2019.

Quispe, P. (2003). Ecosistema de manglar en concesión en El Oro. Seminario Binacional de Manglares: Promoviendo el cambio de experiencias en manejo sostenible de los manglares fronterizos PeruanosEcuatorianos 13 y14 de noviembre del 2003. Fundación Peruana para la Conservación de la NaturalezaPronaturaleza y Fundación Ecológica Arco Iris de Ecuador.

Rendón, M., Suárez, E., y Mejía, M. (2004). Manejo sustentable y comercialización de concha prieta en cautiverio en Puerto El Morro (Provincia de Guayas) para su exportación hacia España. Escuela Superior Politécnica del Litoral, Facultad de Ciencias Humanísticas y Económicas. Guayaquil, Ecuador. ESPOL. 9 pp. 
Rengifo, W. (1985). Estudio comparativo de 8 especies del género Anadara con énfasis en algunos aspectos biológicos, económicos y bromatológicos en el mercado. Tesis Universidad del Valle. Bahía de Buenaventura. Colombia. 125 pp.

Robles-Mungaray, M., Mazón-Suástegui, J., Flores-Higuera, F. Y., y Garzón-Favela, J. (1999). Experiencias en la producción de larvas y semillas de Anadara grandis (Broderip y Sowerby, 1839) en laboratorio. VII Congreso de la AIMAC y primer Simposio Internacional sobre el Mar de Cortez. Centro de Investigaciones Biológicas del Noroeste, S.C., (CIBNOR). Hermosillo Sonora, México.

Samaniego, E. (2008). Cultivo de concha prieta Anadara tuberculosa a diferentes densidades en estanques camaroneros utilizando canastas de cultivo. Tesis de Ingeniería en Acuicultura. Universidad Técnica de Machala, Facultad Ciencias Agropecuarias, Escuela de Acuacultura. Ecuador. 63 pp.

Sandoval, E., y Saborío, A. (2008). Calidad bacteriológica del agua en los sitios de recolección de "conchas negras" (Anadara tuberculosa y Anadara similis) en Chinandega, Nicaragua. Encuentro, XL(81), 30-47.

SIBM- Sistema de Información sobre Biodiversidad Marina de Colombia e INVEMAR- Instituto de Investigaciones Marinas y Costeras José Benito Vives De Andréis, Colombia. (2008). Sistema de Información sobre Biodiversidad Marina de Colombia. Base de datos en línea. Recuperado de URL: http://www.INVEMAR.org.co/siam/sibm/index.htm. Consulta 17.06.2019.

Silva, A., y Bonilla, R. (2001). Abundancia y morfometría de A. tuberculosa y A. similis (Mollusca: Bivalvia) en el manglar de Purruja, Golfo Dulce, Costa Rica. Rev. Biol. Trop., 49(Supl. 2), 315-320.

Silva-Benavides, A. M., y Bonilla, R. (2015). Estructura de la población y distribución de Anadara tuberculosa Sowerby (1833) (Mollusca: Bivalvia) en los manglares de Golfito y Playa Blanca de Puerto Jiménez, Golfo Dulce, Costa Rica. Rev. Biol. Trop. (Int. J. Trop. Biol. ISSN-0034-7744), 63(Suppl. 1), 287-298.

Urrutia, G.X., Navarro, J.M., Clasing, E., \& Stead, R. A. (2001). The effects of environmental factors on the biochemical composition of the bivalve Tagelus dombeii (Lamarck, 1818) (Tellinecea: Solecurtidae) from the intertidal flat of Coihuín, Puerto Montt, Chile. J. Shellfish Res., 20: 1077-1087.

Villalobos, C., y Báez, A. (1983). Tasa de crecimiento y mortalidad en Anadara tuberculosa (Bivalvia: Arcidae) bajo dos sistemas de cultivo en el Pacífico de Costa Rica. Rev. Lat. Acui., 17, 1-18.

Vega, A. J. (1994). Estructura de población, rendimiento y épocas reproductivas de Anadara spp. (Bivalvia: Arcidae) en la Reserva Forestal Térraba-Sierpe, Puntarenas, Costa Rica, con recomendaciones para su manejo. Tesis de Maestría, Universidad de Costa Rica, San José, Costa Rica. 114 p.

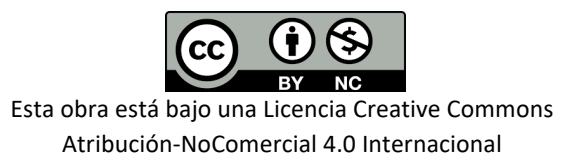

